\title{
A new Borrelia on the block: Borrelia miyamotoi - a human health risk?
}

Sally Cutler ${ }^{1}$, Muriel Vayssier-Taussat ${ }^{2}$, Agustín Estrada-Peña ${ }^{3}$, Aleksandar Potkonjak ${ }^{4}$, Andrei Daniel Mihalca ${ }^{5}$, Hervé Zeller ${ }^{6}$

1. School of Health, Sport \& Bioscience, University of East London, London, United Kingdom

2. INRA, UMR BIPAR INRA, ENVA, Anses, Maisons-Alfort, France

3. Department of Animal Health, Faculty of Veterinary Medicine, University of Zaragoza, Spain

4. Department of Veterinary Medicine, Faculty of Agriculture, University of Novi Sad, Serbia

5. Department of Parasitology and Parasitic Diseases, University of Agricultural Sciences and Veterinary Medicine Cluj-Napoca, Romania

6. European Centre for Disease Prevention and Control, Solna, Sweden

Correspondence: Sally J. Cutler (s.cutler@uel.ac.uk)

Citation style for this article:

Cutler Sally, Vayssier-Taussat Muriel, Estrada-Peña Agustín, Potkonjak Aleksandar, Mihalca Andrei Daniel, Zeller Hervé. A new Borrelia on the block: Borrelia miyamotoi - a human health risk?. Euro Surveill. 2019;24(18):pii=1800170. https://doi.org/10.2807/1560-7917.ES.2019.24.18.1800170

Background: Borrelia miyamotoi clusters phylogenetically among relapsing fever borreliae, but is transmitted by hard ticks. Recent recognition as a human pathogen has intensified research into its ecology and pathogenic potential. Aims: We aimed to provide a timely critical integrative evaluation of our knowledge on $B$. miyamotoi, to assess its public health relevance and guide future research. Methods: This narrative review used peer-reviewed literature in English from January 1994 to December 2018. Results: Borrelia miyamotoi occurs in the world's northern hemisphere where it co-circulates with $B$. burgdorferi sensu lato, which causes Lyme disease. The two borreliae have overlapping vertebrate and tick hosts. While ticks serve as vectors for both species, they are also reservoirs for $B$. miyamotoi. Three $B$. miyamotoi genotypes are described, but further diversity is being recognised. The lack of sufficient cultivable isolates and vertebrate models compromise investigation of human infection and its consequences. Our understanding mainly originates from limited case series. In these, human infections mostly present as influenza-like illness, with relapsing fever in sporadic cases and neurological disease reported in immunocompromised patients. Unspecific clinical presentation, also occasionally resulting from Lyme- or other co-infections, complicates diagnosis, likely contributing to underreporting. Diagnostics mainly employ PCR and serology. Borrelia miyamotoi infections are treated with antimicrobials according to regimes used for Lyme disease. Conclusions: With co-infection of tick-borne pathogens being commonplace, diagnostic improvements remain important. Developing in vivo models might allow more insight into human pathogenesis. Continued ecological and human case studies are key to better epidemiological understanding, guiding intervention strategies.

\section{Introduction}

Borrelia miyamotoi, which belongs to the relapsing fever clade within the Borrelia genus, was first described in 1994 with its detection in Ixodes persulcatus ticks in Japan [1]. It was named after Professor Kenji Miyamoto who initially reported this spirochaete from Hokkaido, Japan. Its potential to cause human disease was not realised until 2011 when Platonov and colleagues described a series of cases of $B$. miyamotoi infection in Russia [2].

It is now established that this spirochaete has a global distribution and co-circulates with the related agent of Lyme borreliosis (Lyme disease), B. burgdorferi sensu lato (s.l.), which uses the same tick species as vectors, albeit at a lower frequency [3-9]. Similar to the Lyme borreliae, where different tick species endemic to specific regions of the globe serve as vectors, $B$. miyamotoi is found in multiple tick species that reside constrained by compatible geo-ecological habitats [2-4,10-13].

The objectives of this review were threefold: (i) to collate the rapid expansion of research findings on $B$. miyamotoi and its ecological interactions; (ii) to review the public health significance of $B$. miyamotoi and to (iii) highlight knowledge gaps in our understanding of this microbe and its importance as a human pathogen, thus focussing direction for future research.

\section{Methods}

We performed a non-systematic narrative literature review. Literature searches were thus not fully exhaustive. Reports relating to the search term 'Borrelia miyamotoi' published in English and indexed in biomedical databases including EBSCO (Academic Search Complete), Scopus and Science Direct were sought 
(Figure 1). These dated from the first description of B. miyamotoi in January 1994 to December 2018. Duplicate records were removed and articles were further screened, first by reading the titles and abstracts, then the full reports. Prioritisation to those papers that contributed original knowledge to our understanding was given. Supplementary literature was used to further support discussions beyond primary searches where justifiable (Figure 1).

\section{Results}

\section{Epidemiology}

Borrelia miyamotoi is being increasingly documented from the world's northern hemisphere. This spirochaete has been recorded in Canada as well on the east and west coasts of the United States (US). It has also been observed in numerous European countries (including the Czech Republic, Denmark, Estonia, France, Germany, Netherlands, Norway, Poland, Romania, Sweden and Switzerland) as well as in Russia through to Japan $[3,10,14,15]$.

Surveys to detect $B$. miyamotoi have tended to reflect local research interest rather than being systematic epidemiological studies. These have however established that endemic areas for $B$. miyamotoi overlap with those for Lyme borreliae (B. burgdorferi s.l.), and during tick surveys, specimens co-infected with both spirochaetes have been identified $[4,11,16]$. In several countries, prevalence studies based upon individual ticks infected with borreliae have noted lower rates of ticks infected with $B$. miyamotoi than with Lymeassociated borreliae $[5,17]$.

Among 20 studies found in this review, from countries reporting clinical cases and $B$. miyamotoi prevalence in ticks, infection rates in ticks ranged from 0.02 to $6.4 \%$, although most studies reported a range between 1 and $2 \%$ (Table 1) $[3,5,15,18,19]$. Nevertheless, pockets of higher infection rates have been described. In Napa County, California, US, for example, $15.4 \%$ of adult ticks (10/65 I. pacificus) studied were infected with $B$. miyamotoi [3] compared with a background infection level of $1.4 \%(44 / 3,255)$ of nymphs of this same species [19]. Moreover, in a study in Kurgan, Russia, 16\% of ticks (26/162 I. persulcatus) were found infected [2]. These rates might reflect either hyperendemic areas or local efficient transmission events.

In some countries, such as Mongolia, where relatively high levels of tick infections with $B$. miyamotoi $(4.5 \%$; 48/1,069 I. persulcatus) have been detected, no human cases were reported [10]. This was similar in the town of Hannover, Germany, where a tick-infection prevalence of $8.9 \%$ ( $45 / 505 \%$. ricinus ticks) was reported but no infections in people [20]. On the other hand, on Hokkaido Island, Japan, where, depending on the tick species, $2 \%(71 / 3,532$ l. persulcatus) and 4.3\% (5/117 I. pavlovskyi) of ticks were infected, human cases did occur [4]. Human cases were also observed in the
Irkutsk region, Russia, where an overall $2.9 \%$ prevalence of tick infection has been estimated [21] (Table 1). In Yekaterinburg and Izhervsk, where clinical cases were first described, tick (I. persulcatus) infection prevalence rates of $0.9 \%(4 / 442)$ and $6.3 \%$ (25/394) were respectively found. Estimated incidence of human infection with $B$. miyamotoi in Yekaterinburg is likely to be 1 per 100,000 per year, accounting for a quarter of tick-borne borreliosis cases within this province $[2,22]$.

\section{Phylogeny and diversity of Borrelia miyamotoi} The taxonomic definition of the genus Borrelia is currently debated with the suggestion that the Lyme disease associated members be removed from this genus, and instead be placed in a new genus, Borreliella [23]. This suggestion has not been met with universal approval, with some experts suggesting this division is premature given the current discovery of new spirochaetes $[24,25]$. Borrelia miyamotoi clusters among the relapsing fever spirochaetes, but unlike these, resides alongside $B$. theileri and $B$. lonestari that are also transmitted by hard ticks (Figure 2). Until recently, it was believed that $B$. miyamotoi fell into three geographically separated clades (genotypes), namely the Asian (or Siberian), European and American, (Figure 2, Table 2), transmitted by I. persulcatus/I. pavlovskyi (I. ovatus), I. ricinus and I. scapularis or I. pacificus, respectively $[26,27]$.

However, as knowledge of this particular spirochaete increases, more diversity within the species is being recognised. A slight sequence variation was observed among the Asian clade based upon 16S sequence data, typified by strain Y14T1 from I. persulcatus ticks (Figure 2) that revealed sequence divergence from other members within this clade [10]. Similarly, in the US, divergence was noted among sequence types of American $B$. miyamotoi associated with I. pacificus (Figure 2) $[12,28]$. Given the highly conserved nature of $16 \mathrm{~S}$, it is not generally considered a reliable marker for the delineation of borreliae [29], as such, the level of heterogeneity among these variants might be considerably more than that inferred from $16 \mathrm{~S}$ data alone.

A potential fourth clade was recently described for strains found in $I$. ovatus ticks in Japan. These showed clear separation from the established sequence types for $16 \mathrm{~S}$ rRNA (Figure 2) and the clade was further confirmed using more discriminatory multilocus sequence typing (MLST) phylogenetic approaches [30]. Representatives of this potentially novel clade of $B$. miyamotoi were carried by up to $0.6 \%$ of ticks collected from Honshu Island, but were absent from those ticks collected in Hokkaido, Japan $[4,10]$.

Strains belonging to different genotypes of $B$. miyamotoi have been observed to geographically overlap. Asian and European genotypes have been detected in Russia and Estonia $[2,11]$. In south-eastern Estonia, the Asian strains were detected in both I. persulcatus and I 


\section{FIGURE 1}

Flow chart of the search strategy and inclusion of identified articles, narrative literature review of Borrelia miyamotoi

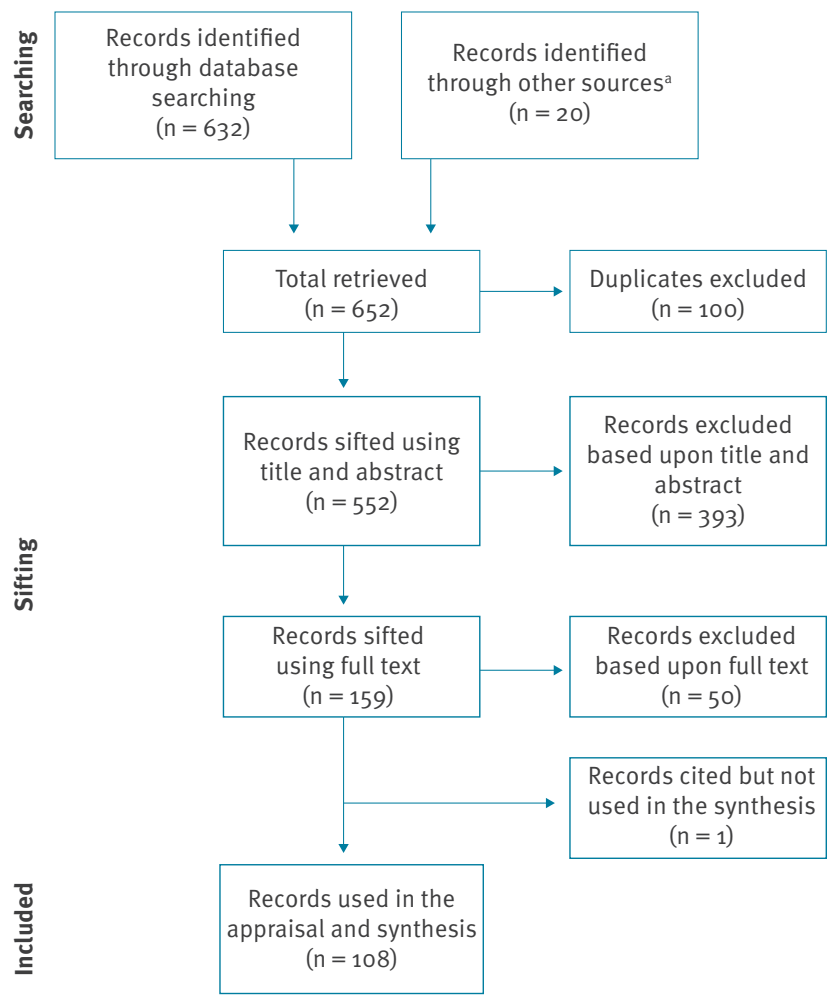

Literature used was derived from sifting EBSCO, Science Direct and Scopus databases searching for 'Borrelia miyamotoi' from lanuary 1994 through to December 2018.

${ }^{a}$ Additional supplementary information was included as indicated to support discussion points as required. This included information on the pathobiology of other relapsing fever species.

ricinus while the European strains could only be found in $I$. ricinus [11].

The situation in Estonia also illustrates that a single tick species (e.g. I. ricinus) can harbour several genotypes [11], a phenomenon that has also been observed for I. ovatus, which can be infected by both the Asian and the new variant genotype [10]. On the other hand, some genotypes have been found in multiple tick species such as the American strain found in I. scapularis and I. dentatus [31], with its close variant present in $I$. pacificus [12]. Furthermore, there are reports of Asian clade representatives of $B$. miyamotoi in other types of ticks such as Haemaphysalis concinna [13] and $H$. longicornis [32], but the ecological role of these species for maintaining this spirochaete has not been fully elucidated. Thus vector specificity may not be as strict as previous data suggested.

\section{Ecology}

In studies assessing single strains of $B$. miyamotoi and their associated tick species, the spirochaete has been detected among unfed larval ticks, suggesting successful transovarial (i.e. vertical) transmission to successive generations of ticks. Thus, ticks should be considered as both vectors and reservoirs for $B$. miyamotoi. Vertical transmission is estimated to have a frequency of less than 0.8 per tick generation, thus not sufficient to sustain $B$. miyamotoi for more than a few successive generations, in isolation of other transmission mechanisms $[6,33]$. That such mechanisms are needed has gained further support from laboratory-based in vivo infection studies suggesting a decline of tick infection by $B$. miyamotoi during their development, through trans-stadial moults [34]. Prevalence studies conducted with different $B$. miyamotoi tick instars revealed lower infection rates among larvae than among nymphal and adult ticks (which had equivalent rates) [35]. The higher infection rates in nymphs and adults possibly result from infection of ticks by feeding (i.e. horizontal transmission) later in their life cycle. This contrasts with a staged infection rate by instar reported for B. burgdorferi s.l. $[11,17]$, whereby infection may occur predominantly by horizontal transmission (i.e. feeding).

Similar to other borreliae, prevalence of B. miyamotoi appears to be amplified through infection of certain avian and rodent species. Varied small vertebrate species have been shown to be competent reservoirs of infection by $B$. miyamotoi including mice (Apodemus spp. and Peromyscus spp.), voles (Microtus spp., Myodes glareolus, and Microtus arvalis), chipmunks (Tamias sp.), squirrels (Sciuridae spp.), European hedgehogs (Erinaceus europaeus) and racoons (Procyon spp.) [6-8,15,31,36-39]. Avian species have not been extensively surveyed, but $B$. miyamotoi has been detected in blackbirds (Turdus merula), great tits (Parus major), common chiffchaff (Phylloscopus collybita), song thrush (Turdus philomelos), European robin (Erithacus rubecula) and European greenfinch (Chloris chloris) albeit at low levels 0.6$8 \%$ of avian-removed ticks $[15,31,40]$. A report from Tennessee, US describes a surprisingly high level of $B$. miyamotoi infection among wild turkeys (Meleagris gallopavo) with $58 \%$ (35/60) birds sampled testing positive for $B$. miyamotoi [41]. These birds were heavily infested with $A$. americanum ticks (70\%; 42/60), but none of the ticks were positive for $B$. miyamotoi [41].

Furthermore, larger vertebrates have been found with evidence of infection such as wild boar $[42,43]$ but their ecological significance remains unclear. Interestingly, deer have been suggested to amplify $B$. miyamotoi tick infection rates in the US [44] and representatives of the Asian genotype of $B$. miyamotoi have been recovered from infected deer in the far East [32]. These observations contrast with the Lyme borreliae, where deer are not competent species to enhance transmission to ticks during feeding. Nevertheless, it must be noted 
that a study from Japan failed to demonstrate $B$. miyamoto $i$ in deer, but instead reported another hard-tick vectored borrelial species resembling $B$. theileri and $B$. lonestari [45] that had been previously reported from Japanese Haemaphysalis spp. ticks [46] and $H$. longicornis from China [32]. A role for deer was also not corroborated by a study from the Netherlands and the European genotype [15]. Because the various studies reported here were based upon different $B$. miyamotoigenotypes, strain differences might explain the differences observed for transmission efficiency following ticks feeding upon deer.

\section{Relations between Borrelia}

miyamotoi and Borrelia burgdorferi s.l.

In vertebrates, co-infection with $B$. miyamotoi and $B$. burgdorferi has been recorded, but the probability of dual infection appears no greater than that which would be expected independently by chance [6].

In ticks however, it remains a question whether coinfection happens at random or not. Some studies suggest that co-infection is more frequent than either infection alone [15]. Others however suggest that this happens by chance. For example, subsequent to a study finding $264 / 5,431(4.9 \%)$ B. burgdorferi sensu stricto in nymphal $/$. pacificus ticks, a subset of 3,255 ticks was retested for B. miyamotoi. A total of 44 (1.4\%) ticks were infected $B$. miyamotoi alone, and only one single individual with $B$. burgdorferi sensu stricto was also found co-infected with $B$. miyamotoi $[19,47]$. On the other hand, among I. scapularis ticks from Midwestern US, Hamer et al. report a 2.1 times lower level of co-infection with $B$. burgdorferi and $B$. miyamotoi (0.05\% co-infection among 1,565 questing adult ticks) than expected by chance [48].

Tick surveillance demonstrates that $B$. burgdorferi s.l. is more prevalent than $B$. miyamotoi, approximating to a ratio of 10:1 or greater in several studies $[5,6,48,49]$. This is intriguing given that an American study suggests that both species infect ticks to equivalent levels achieving infection rates of around 2,000 spirochaetes for nymphs and 5,000 for adult ticks (sometimes higher in the case of $B$. miyamotoi) [6]. A European study, which quantified by PCR B. miyamotoi in feeding ticks removed from humans, even reported considerably higher borrelial tick loads by $B$. miyamotoi (mean count of $2.1 \times 10^{5}$ ) than by $B$. burgdorferi s.l. (with a mean of $4.5 \times 10^{3}$ for $B$. afzelii and $2.7 \times 10^{3}$ for $B$. garinii) [49]. Thus, infection prevalence among ticks is higher for $B$. burgdorferi s.l. $[5,6,48,49]$, however, B. miyamotoiinfected ticks appear to have equivalent [6], or higher quantities of borreliae within their tissues [49].

The answer to why we observe higher prevalence for $B$. burgdorferi s.l. compared with $B$. miyamotoi in ticks, might reside in the superior ability for $B$. burgdorferi to persist in the skin of its vertebrate host, potentially extending the window of transmission to other feeding ticks. The failure to detect $B$. miyamotoi in the skin of erythema migrans patients corroborates this theory [15]. Moreover, studies of Peromyscus leucopus mice during $I$. scapularis nymphal questing times have shown that Lyme-associated borreliae resided in the skin of their host, while $B$. miyamotoi gave a higher blood burden with density counts five times higher than B. burgdorferi s.l [6]. While levels up to 251 spirochaetes of $B$. miyamotoi per $\mathrm{mL}$ blood have been observed, persistence in blood within an infected vertebrate appears comparable to $B$. burgdorferi s.l. $[6,50]$.

The sympatric overlap of $B$. burgdorferi s.l. and $B$. miyamotoi begs the question as to how these closely related spirochaetes might interact. Remarkably, the prevalence of $B$. miyamotoi infection in ticks appears indifferent to variations in the habitat type, or to ecological influences that impact upon the prevalence of $B$. burgdorferi s.l. [19]. As nutritional requirements are likely to overlap, is there antagonism between these species, indifference or a more synergistic relationship? Competitive interactions have not been explored per se, however, emerging data suggest that these species appear indifferent to each other. A study of shared small rodent hosts suggests different seasonal peaks of infection, with $B$. burgdorferi s.l. rodent infection peaking in spring and being driven by nymphs, whereas $B$. miyamotoi rodent infection being predominant in summertime through larval ticks $[51,52]$. This separation might provide a means for both spirochaetes to co-exist [6]. Indeed, transovarial tick transmission of $B$. miyamotoi enables larval ticks to be infectious for their subsequent hosts. In contrast, tick larvae harbouring $B$. burgdorferi s.l. are rarely reported, suggesting infrequent vertical transmission in $B$. burgdorferi s.l. Among field-collected larvae, a study found $B$. burgdorferi s.l. in $0.62 \%$ as opposed to $2 \%$ for $B$. miyamotoi [53]. Some recent publications query whether previously reported low levels of $B$. burgdorferi s.l. vertical transmission constituted in fact detection of $B$. miyamotoi $[54,55]$.

Transmission to humans, magnitude of human infection and pathogenesis

Emerging evidence supports presence of B. miyamoto $i$ in tick salivary glands [34], with a study finding that over $88 \%$ of second generation progeny of infected $I$. scapularis nymphal ticks had B. miyamotoi in their salivary glands, as seen with other relapsing fever spirochaetes in their soft tick vectors [56]. Experimental mouse (CD-1 outbred Mus musculus mice) transmission studies using ticks derived from a field collected population infected with the American strain of $B$. miyamotoi, have demonstrated $10 \%$ infection after $24 \mathrm{hrs}$, rising to $31 \%$ at $48 \mathrm{hrs}$ and $63 \%$ by $72 \mathrm{hrs}$ [56]. Though not as rapid as the transmission of classical relapsing fever spirochaetes by their soft tick vectors [57], this demonstrates transmission of $B$. miyamotoi in the first day of tick attachment, contrasting with the days of attachment needed by Lyme borreliae to migrate from the tick midgut to salivary glands for transmission [57]. 
Studies worldwide reporting Borrelia miyamotoi infections, with diagnostic methods, prevalence and human clinical signs, 1994-2018

\begin{tabular}{|c|c|c|c|c|c|c|}
\hline Location & $\begin{array}{l}\text { Borrelia miyamotoi } \\
\text { cases with } \\
\text { reference (year of } \\
\text { publication) }\end{array}$ & $\begin{array}{l}\text { Percentage } \\
\text { of cases } \\
\text { among } \\
\text { persons } \\
\text { studied }\end{array}$ & $\begin{array}{l}\text { Reported infection } \\
\text { prevalence in ticks }\end{array}$ & Clinical signs & $\begin{array}{l}\text { Diagnostic } \\
\text { method }\end{array}$ & $\begin{array}{c}\text { References for } \\
\text { prevalence in ticks and } \\
\text { human cases }\end{array}$ \\
\hline Russia & $\begin{array}{l}51 / 302 \text { humans } \\
\text { bitten by ticks } \\
\text { (2011) [2] }\end{array}$ & $16.9 \%$ & \multirow{3}{*}{$\begin{array}{l}\text { Ixodes ricinus } 0.8 \% \\
\text { I. persulcatus } \\
2.9-10.5 \% \\
\text { I. pavlovski } 6.4 \%\end{array}$} & $\begin{array}{c}\text { Fever, chills, sweating, } \\
\text { headache, fatigue and } \\
\text { vomiting (relapsing } \\
\text { fever in 5) }\end{array}$ & $\begin{array}{l}\text { PCR and } \\
\text { serology }\end{array}$ & {$[2,21,104,105]$} \\
\hline $\begin{array}{l}\text { Izhevsk, } \\
\text { Russia }\end{array}$ & $\begin{array}{l}\text { 2/24 B. miyamotoi } \\
\text { infected-tick bites } \\
\text { developed disease } \\
\text { (2015) [58] }\end{array}$ & $8.3 \%$ & & $\begin{array}{l}\text { Fever, chills, sweating, } \\
\text { headache, fatigue, } \\
\text { nausea, vomiting, } \\
\text { dizziness. }\end{array}$ & $\begin{array}{l}\text { PCR and } \\
\text { serology }\end{array}$ & {$[58]$} \\
\hline $\begin{array}{l}\text { Yekaterinburg, } \\
\text { Russia }\end{array}$ & $\begin{array}{l}71 / 459 \text { tick-borne } \\
\text { infection (including } \\
1^{\text {a }} \text { also with Lyme } \\
\text { borreliosis) (2018) } \\
\text { [22] }\end{array}$ & $15 \cdot 5 \%$ & & $\begin{array}{l}\text { Clinical details not } \\
\text { described. }\end{array}$ & $\begin{array}{l}\text { PCR and } \\
\text { serology }\end{array}$ & {$[2,22]$} \\
\hline China & $\begin{array}{c}\text { 14/984 patients } \\
\text { with tick-borne } \\
\text { infection }(2018)[13]\end{array}$ & $1.4 \%$ & \begin{tabular}{|c|} 
I. persulcatu s3\% \\
Hyaloma concinna $2.8 \%$
\end{tabular} & $\begin{array}{l}\text { Fever, headache, } \\
\text { anorexia, asthenia, } \\
\text { arthralgia }\end{array}$ & PCR & {$[13]$} \\
\hline $\begin{array}{l}\text { Hokkaido, } \\
\text { Japan }\end{array}$ & $\begin{array}{l}2^{\mathrm{a}} / 408 \text { Lyme } \\
\text { borreliosis cases } \\
(2014)[75]\end{array}$ & $0.49 \%$ & \multirow{3}{*}{$\begin{array}{c}\text { I. persulcatus } 1.6-2 \% \\
\text { I. pavlovski } 4.3 \% \\
\text { I. ovatus } 0.5 \%\end{array}$} & $\begin{array}{l}\text { Fever, myalgia, } \\
\text { anorexia }\end{array}$ & $\begin{array}{l}\text { PCR and } \\
\text { serology }\end{array}$ & {$[4,10,75]$} \\
\hline Japan & $\begin{array}{l}\text { 12/459 suspected } \\
\text { Lyme borreliosis } \\
(2018)[64]\end{array}$ & $2.6 \%$ & & $\begin{array}{c}\text { One case } \\
\text { meningoencephalitis; } \\
\text { clinical history not } \\
\text { disclosed on remainder. }\end{array}$ & Serology & {$[4,10,64]$} \\
\hline $\begin{array}{l}\text { Hokkaido, } \\
\text { Japan }\end{array}$ & $\begin{array}{l}1 \text { case study (2017) } \\
{[80]}\end{array}$ & NA & & $\begin{array}{l}\text { Fever, macular } \\
\text { erythematous rash, } \\
\text { low blood pressure, } \\
\text { thrombocytopenia. }\end{array}$ & Serology & {$[4,10,80]$} \\
\hline Germany & $\begin{array}{c}1 \text { case study } \\
\text { suspected Lyme } \\
\text { neuroborreliosis } \\
(2016)[72]\end{array}$ & NA & I. ricinus $1.2-2.4 \%$ & $\begin{array}{c}\text { Lymphomatous } \\
\text { meningitis } \\
\text { (immunocompromised) }\end{array}$ & $\begin{array}{c}\text { PCR } \\
\text { CXCL13 and } \\
\text { microscopy }\end{array}$ & {$[3,5,72,82]$} \\
\hline Netherlands & $\begin{array}{c}1 \text { case study (2013) } \\
{[73]}\end{array}$ & NA & \multirow{2}{*}{ I. ricinus $2.1-3.6 \%$} & $\begin{array}{l}\text { Meningoencephalitis } \\
\text { (immunocompromised) }\end{array}$ & \begin{tabular}{|} 
Microscopy, \\
PCR and \\
equivocal \\
serology
\end{tabular} & {$[15,73,106,107]$} \\
\hline Netherlands & $\begin{array}{l}1 \text { case study (2018) } \\
{[103]}\end{array}$ & NA & & $\begin{array}{l}\text { Lymphadenopathy, } \\
\text { leucopenia and } \\
\text { thrombocytopenia } \\
\text { (immunocompetent) }\end{array}$ & Serology & {$[15,103]$} \\
\hline United States & $\begin{array}{l}97 / 11,515 \text { acute } \\
\text { febrile patients } \\
\quad(2015)[78]\end{array}$ & $0.84 \%$ & $\begin{array}{c}\text { I. scapularis } 0.02-3.1 \% \\
\text { I. pacificus } 0.4-2 \%\end{array}$ & $\begin{array}{c}\text { Fever, chills, myalgia, } \\
\text { arthralgia, headaches, } \\
\text { neutropenia, } \\
\text { thrombocytopenia }\end{array}$ & PCR & {$[3,6,18,19,35,78,83,108]$} \\
\hline
\end{tabular}

NA: not applicable.

a Denotes dual-infected cases who also presented with erythema migrans lesions.

In this respect, in humans, transmission efficiency has been estimated at 8.3\% [58], based upon a cohort of 24 persons bitten by PCR-positive ticks, of whom only two later developed compatible clinical disease [58]. By comparison, three of 68 (4.4\%), humans bitten by $B$. burgdorferi s.l. infected ticks, developed disease (erythema migrans) $[58,59]$.

In terms of the magnitude of human infections with B. miyamotoi, this depends to some extent on the frequency of tick bites among people and on the prevalence of tick infection. Ixodid ticks are holarctic in distribution and assessments of tick bites vary by country and location. In the Netherlands, it was estimated that tick bites amount to 71,980 per million inhabitants (2007) [60]. In the Irkutsk region in Russia 2014 , tick bites were estimated at 12,500 per million people [21]. The prevalence of infection among ticks ranges from 0.5 to $6 \%$ in many regions of the northern hemisphere. Taken together with a transmission rate of $8.3 \%$ [58], it is likely that human infections are underestimated [61]. 
In Yekaterinburg Province, Russia in 2009, it was estimated B. miyamotoi infections occur in 1 per 100,000 inhabitants [2]. Studies from the Netherlands suggest that some 36,000 humans are bitten each year by $B$. miyamotoi (European strain) infected ticks [9]. Serological studies from the US appear to corroborate human exposure $[62,63]$. Despite this, reports of human infections are comparatively few; for example, retrospective serological evaluation of sera from cases suspected for Lyme disease only detected 19 indigenous cases in Japan between 2013 and 2017 [64].

Borreliae as a group, are renowned for their ability to persist within humans. Relapsing fever Borrelia undergo an elaborate series of antigenic variation coupled with other mechanisms such as binding factor $\mathrm{H}$ and evading the components of the complement cascade, enabling their persistence in blood or their human host over time. Likewise, B. miyamotoi possesses variable membrane proteins (vmp) that could facilitate relapse with different antigenic variants [65], and has the ability to bind factor $\mathrm{H}$ and related proteins, thus evading host complement-mediated degradation [66-68]. Clinical reports of relapse with $B$. miyamotoi infection are described in the literature, however surprisingly, this appears less frequently than seen with classical relapsing fever infections $[2,69]$.

The borreliae have proven neurotropism potential, using the nervous system as an immunologically protected niche enabling persistence in their vertebrate host $[70,71]$. The precise mechanisms by which spirochaetes exploit this niche are poorly understood, but animal studies have shown that relapsing fever Borrelia can survive for 270 days within this site, thus enabling greater in vivo persistence [70]. Neurological sequelae have been a feature of infection among immunocompromised individuals (see clinical presentations below) [72-74]. An in vivo infection model is urgently needed to unravel the pathogenesis of human B. miyamotoi infection. A severe combined immune deficiency (SCID) mouse model has been established [34], but has limitations to extrapolate to infection in immunocompetent humans.

\section{Clinical presentation}

Clinical cases have been reported from Europe, Japan [4,64,75], China [13], Russia [2] and the US [76-78]. Infection with $B$. miyamotoi does not present with obvious hallmark signs. Instead, patients present with fever accompanied by non-specific influenza-like symptoms, such as chills, fatigue, headache, myalgia and arthralgia (Table 1) [9].

Although $B$. miyamotoi clusters within the relapsing fever group of spirochaetes, cases with the characteristic recurring febrile episodes interspersed with nonfebrile intervals that typify classical relapsing fever have only been described sporadically $[2,79]$. In these, up to three febrile episodes have been recorded [2], however this might be an underestimation given that patients are typically managed with antimicrobial therapy upon diagnosis. A case who was retrospectively diagnosed following spontaneous recovery had a documented relapsing illness with two episodes, albeit with a lengthy 3-week afebrile period [69].

Furthermore, unlike relapsing fever spirochaetes, epistaxis, abortion, jaundice and major organ failure have not appeared as features of $B$. miyamotoi infection. Nevertheless, both $B$. miyamotoi and classical relapsing fever share fever, headaches, chills, myalgia, arthralgia, and nausea/vomiting.

Some differences in clinical presentation have been noted between US and Russian cases, particularly regarding the presence of thrombocytopenia documented in approximately half of American cases [78], but not reported from those in Russia. This differential clinical presentation may be an artefact given the recent description of thrombocytopenia in a Japanese clinical case infected with an Asian B. miyamotoi strain [80], akin to those reported from Russian cases.

In two studies, cases have been reported with erythema migrans $[75,78]$, however it is likely that these had concomitant infection with $B$. burgdorferi s.l., thus representing co-infections. Indeed, one of these studies retrospectively sought presence of $B$. miyamoto $i$ in sera from cases diagnosed with Lyme disease, whereas the other reported one case of erythema migrans among $51 \mathrm{~B}$. miyamotoi patients who had an overall $14 \%$ co-infection rate with $B$. burgdorferi s.l. A larger study of 71 PCR-confirmed $B$. miyamotoi infected cases from Yekaterinburg, Russia, found only five of these cases with erythema migrans [22]. Analysis of blood for confirmation of pathogens disclosed that one case was co-infected with $B$. burgdorferi s.l., but it was concluded that the remaining cases with erythema migrans were realistically also co-infections given the poor sensitivity of PCR to detect Lyme disease using blood samples (as B. burgdorferi s.l. tends to be found in the skin) $[22,49]$.

Borrelia miyamotoi, like other members of the borreliae have demonstrated their ability to result in neurological sequelae with descriptions of meningoencephalitis, albeit among immunocompromised individuals [64,7274]. Unlike the acute febrile presentation described above, infections in these immunocompromised cases described to date, have shown a more insidious onset, often over several months. One case presented with memory deficits and disturbed gait, with lumbar puncture revealing pleocytosis and raised cerebrospinal fluid (CSF) protein [73].

\section{Diagnostics}

For immunocompromised patients, diagnosis with microscopy has been used to a certain extent [72-74], sometimes combined with immunofluorescence [74]. For example, in three case reports on immunocompromised patients infected with $B$. miyamotoi [72-74], 


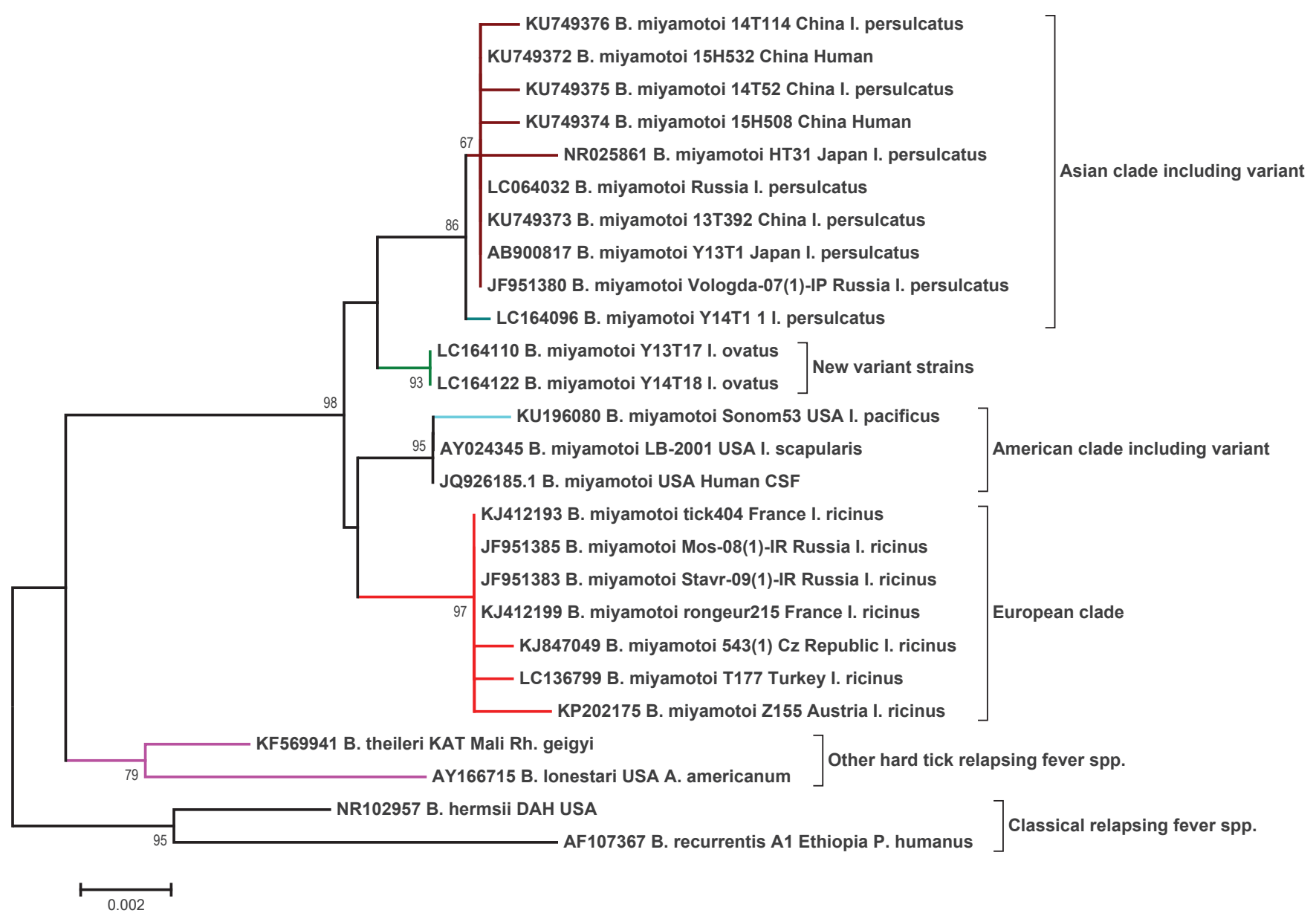

European, American and Asian clusters are demonstrated alongside newly described strains, using classical relapsing fever species and other hard tick borreliae as outgroups. The colours of the branches denote the different clades and highlight variant strains. Tree labels provide GenBank accession numbers; strain reference; country of origin and source of sequence. The tree was compiled using a neighbour-joining algorithm, with clusters assessed using the bootstrap test for stringency (1,000 replicates). The percentages of replicate trees in which the associated isolates clustered together are shown next to the branches. The tree is drawn to scale, with branch lengths in the same units as those of the evolutionary distances used to infer the phylogenetic tree. These units represent the number of base substitutions per site. Evolutionary analyses were conducted in MEGA7.

spirochaetes in the CSF were retrospectively detected by microscopy in one case [73]. For the other two cases, $B$. miyamotoi was also identified by microscopy, albeit after concentration of the CSF sample and either Giemsa or acridine orange staining $[72,74]$. For all three cases, however, microscopy was complemented with PCR for diagnosis confirmation [72-74].

Generally, for overall patients, diagnostic approaches depend on the stage and duration of infection. During the acute phase of infection, the presence of the spirochaete in blood and CSF can been demonstrated using PCR and microscopy. The success of such methods rapidly reduces from the fourth day of disease correlated with depletion in the spirochaetal blood counts [22]. Clinical reports of relapse are described in the literature $[2,69]$. If this occurs, it is likely that direct detection using PCR or microscopy might again be valuable.
Use of concentration methods can improve the diagnostic sensitivity of these techniques $[72,74,81]$. Later in the clinical course, serology is the mainstay diagnostic option.

In terms of PCR/molecular diagnostics during acute stages of infection - and for assessment of non-human vertebrates or ticks -, real-time PCR assays for $B$. miyamotoi based upon either 16S rDNA [6] or the flagellin gene target have been described. The effectiveness of such assays for detection of the newly described $B$. miyamotoivariants nevertheless remains to be established [82]. Given the sympatric nature of $B$. miyamotoi and its closely related Lyme-associated borreliae, a logical strategy would be to utilise a multiplex assay able to screen for both pathogens simultaneously. A multiplex approach is also probably better suited to a diagnostic setting to avoid multistep methods and 
reduce contamination risks that arise at each step. Some studies have suggested assays that differentiate conditions with overlapping clinical presenting features, such as $B$. miyamotoi infection and anaplasmosis [77] and have thus produced multiplex PCR assays to differentiate these infections [83].

Concerning serology, many studies have used the glycerophosphoryl diester phosphodiesterase (GIpQ) antigen expressed by members of the relapsing fever borreliae, but absent from B. burgdorferi s.l. [84]. Assays based upon GIpQ will not be $B$. miyamotoi-specific, but in areas where other members of the relapsing fever borreliae are not prevalent, such assays can be useful for population surveys and diagnosis on nonacute infections [85]. Besides the difficulties of GIpQ assays to distinguish $B$. miyamotoi from other relapsing fever borreliae, it is noteworthy that homologous proteins have been reported from both Klebsiella pneumoniae and Salmonella enterica [86]. In addition to lack of specificity, other reported limitations with the GIpQ antigen-based approach have been poor diagnostic sensitivity, with ability to only detect 28 of 36 convalescent samples from established cases [78].

As the use of vmps as antigens has also been explored for serodiagnosis [87], combinations of GlpQ together with mixtures of highly immunogenic vmps derived from $B$. miyamotoi have been evaluated as a way to improve the diagnostic efficacy [88]. This involved a comprehensive series of 182 PCR-confirmed Russian patients who were followed with sequential sera collected over several months post-infection. Notably, combinations of antigens provided superior sensitivity and/or specificity, with diagnostic titres for IgM, which were reached from 11 to 20 days post-disease onset and for IgG, from 21 to 50 days. This study used blood donor controls and additionally, controls with tick-borne encephalitis recruited from the same geographical region together with controls without tick exposure. Use of the combined antigens resulted in a sensitivity of $94.7 \%$ and specificity of $96.6 \%$ for $\lg M$ from 11 to 20 days post clinical presentation, thus providing important improvements over previous assays [88]. Assessment of duration of serological reactivity in seven of the 182 patients, showed that the IgM response waned within a year, while half $(4 / 7)$ remained seropositive for IgG a year following disease. All individuals had been prescribed antimicrobial therapy.

On a cautionary note, the C6 ELISA used for diagnosing Lyme disease may additionally be positive in those infected by $B$. miyamotoi [69]. Furthermore, when using serological tests to detect $B$. miyamotoi in areas where multiple spirochaetes are endemic, the possibility of serological cross-reactivity between other relapsing fever borreliae such as $B$. hermsii should be kept in mind as this may obscure diagnosis $[64,85]$.

Given the increasing recognition of co-infections among those with tick exposure, it might be prudent to take a more holistic approach and screen for a broader range of tick-borne pathogens than just borreliae [89]. Some diagnostic centres have taken this approach, but many do not yet have the resources for more comprehensive tick-borne pathogen screening.

Isolation of borreliae is always a challenge as these microbes are particularly fastidious to cultivate, requiring complex liquid medium. Isolation is typically confirmed by dark field microscopy. The BarbourStoenner-Kelly (BSK) commercially-available medium (BSK-H) used for B. burgdorferi s.l. is unreliable for growth of relapsing fever spirochaetes (data not shown) and when used for $B$. miyamotoi, is unable to sustain passage of this organism [90]. Growth of $B$. miyamotoi has been achieved using modifications of Kelly-Pettenkofer medium (MKP) $[16,91]$ or in a variation of BSK described as BSK-M [4]. Other studies have used media modifications with inclusion of $50 \%$ serum in order to cultivate these spirochaetes [92].

Propagation of isolates has additionally been achieved using inoculation of SCID mice. Typically, these will show spirochaetes in blood films between 7 and 14 days post-infection [34].

\section{Treatment}

Therapy for $B$. miyamotoi infection has typically followed guidelines used for treatment of Lyme borreliosis. Only a few cultivable strains have been recovered to date, restricting evaluation of different clinical management regimes. Moreover limited in vitro susceptibility testing has been undertaken to verify the efficacy of different therapeutic protocols [93]. Koetsveld and co-authors, noted resistance to amoxicillin in vitro $(16-128 \mathrm{mg} / \mathrm{L})$ using two isolates of $B$. miyamotoi [93]. Interestingly, this feature was also shared by the relapsing fever spirochaete $B$. hermsii that was assessed in parallel. Despite these in vitro findings, a patient treated with amoxicillin (and sultamicillin) responded without complications [80]. No treatment failures have been reported to date, thus it is probable that the hypothesised susceptibility profile being analogous to the Lyme-associated species is supported. Standard methods are not applicable for evaluation of the susceptibility testing of borreliae given their need for liquid cultivation, microaerophilic conditions and coupled with their slow mean generation time [94-96]. Akin to other members of the genus and spirochaetal infections in general, a proportion of patients may develop a Jarisch-Herxheimer reaction (JHR) associated with a sudden exacerbation of clinical signs upon onset of treatment [97]. Though reported, JHR does not appear frequently for cases of acute $B$. miyamotoi infection $[2,74]$.

\section{Future research directions}

Much of the data so far arise from studies designed and funded to look either at tick-borne diseases or more specifically Lyme-associated borreliae. Though valuable, these studies might be biased and not reflect 
Global distribution of Borrelia miyamotoi clades and known vectors as at 2018

\begin{tabular}{|c|c|c|c|c|}
\hline Tick species & Geographical range & $\begin{array}{l}\text { Predominating Borrelia } \\
\text { miyamotoi genotype } \\
\text { (co-occurring variants) }\end{array}$ & $\begin{array}{l}\text { Tick feeding } \\
\text { preference }\end{array}$ & References \\
\hline Ixodes persulcatus & Baltic to Far East & Asian & Generalist & {$[2,11]$} \\
\hline Ixodes pavlovskyi & Western Siberia and Far East & Asian & $\begin{array}{c}\text { Ground foraging birds, } \\
\text { small mammals }\end{array}$ & {$[4,104]$} \\
\hline Ixodes ovatus & South East Asia & $\begin{array}{c}\text { Asian } \\
\text { (new Asian variant) }\end{array}$ & Generalist & {$[4,10]$} \\
\hline Ixodes ricinus & $\begin{array}{l}\text { Northern Sweden to north } \\
\text { Africa, Ireland to Ural in } \\
\text { Russia }\end{array}$ & $\begin{array}{l}\text { European } \\
\text { (Asian) }\end{array}$ & Generalist & {$[11,15]$} \\
\hline Ixodes scapularis & $\begin{array}{l}\text { North-eastern and upper } \\
\text { Midwestern United States }\end{array}$ & American & Generalist & {$[33,44,54]$} \\
\hline Ixodes pacificus & Pacific coast of United States & $\begin{array}{c}\text { American } \\
\text { (new American variant) }\end{array}$ & Generalist & [44] \\
\hline Ixodes dentatus & Eastern United States & American & $\begin{array}{l}\text { Rabbits, hares Birds } \\
\text { (larvae and nymphs) }\end{array}$ & [31] \\
\hline
\end{tabular}

some of the different ecological driving factors underpinning the observed epidemiology of this spirochaete. As such, we still need to more specifically address $B$. miyamotoi epidemiology further. This is important both for risk assessment and for application of control/ intervention strategies. Indeed, many questions remain regarding our understanding of the pathobiology of this spirochaete (Table 3 ).

Future epidemiological studies need to consider the different genotypes of $B$. miyamotoi, particularly in areas of geographical overlap such as in Estonia and Russia $[2,11]$. Ability to assess the epidemiology of $B$. miyamotoi has been enhanced by the development of several multiplex PCR diagnostic methods providing a more cost-effective means for high throughput screening of samples $[6,82,83]$. These approaches, which are tailored to detect genotypes already described, however run the risk of missing hitherto undescribed variants.

Indeed, while three genotypes of $B$. miyamotoi (American, Asian and European) have been previously described, each associated with different tick vectors (Table 2) [3], recent studies have found more diversity within the $B$. miyamotoispecies $[10,12,28]$. Future studies may shed light on how diverse $B$. miyamotoi genotype strains and variants behave. For example, it has not been comprehensively addressed if each of the $B$. miyamotoi genotypes or variants and their respective tick hosts are equally competent for transovarial transmission. Our knowledge to date is based upon studies that typically have only assessed one strain and tick species [33,54]. This information is currently extrapolated to others, but not underpinned by rigorous scientific enquiry.
Despite larger diversity recognised among $B$. miyamotoi strains, the species appears to be less heterogeneous than the $B$. burgdorferi s.l. complex, for which representatives sympatrically overlap with $B$. miyamotoi. Although it needs to be evaluated how strict new $B$. miyamotoi variants are to certain tick species, the variants identified to date have been found to be generally restricted to separate tick species, supporting the idea that, like for other B. miyamotoispirochaetes, ticks still serve as both reservoirs and vectors for these [19]. Conversely, for the Lyme-associated species, ticks act mainly as vectors, while a plethora of vertebrates serve as reservoirs for horizontal infection, potentially driving diversity within this complex.

This being said, vertebrates also play a role in the ecology of $B$. miyamotoi. In this respect, it is notable that high infection rates were reported in turkeys [41]. Studies of avian vertebrates and their role in the ecology of $B$. miyamotoihave largely excluded ground foraging gallinaceous species, which is surprising given their established role as a reservoir for $B$. burgdorferi s.l [98]. Looking into these avian species may provide missing pieces of the jigsaw of understanding the ecological niche of this spirochaete.

Coinfections by $B$. burgdorferi and $B$. miyamotoi have been observed in both vertebrates and ticks. Within ticks, a further level of complexity arises from the growing appreciation of how different microbes might facilitate survival or transmission. An ecological synergy is proposed whereby $B$. burgdorferi s.l. and Babesia microti benefit each other [99], but currently we have no knowledge of such interactions for $B$. miyamotoi. Importantly, we should consider how other pathogens present within ticks (including other Borrelia) will 
TABLE 3

Unanswered questions regarding the pathobiology of Borrelia miyamotoi, 2018

What is the global epidemiological picture of $B$. miyamotoi infection?

Are the different spirochaetal variants restricted among certain tick species?

What is the ecology of this spirochaete?

What is the contribution of high incidence vertebrate species such as wild turkeys towards maintaining the ecological niche for this spirochaete?

What are the consequences of other pathogens present within ticks (including other Borrelia) upon the survival, persistence and

transmissibility of $B$. miyamotoi?

Do different strains show differential virulence within susceptible species?

What are the full range of clinical consequences within humans?

What are human risk factors for development of clinical disease above and beyond being immunocompromised?

Does blood transfusion present a substantive risk for infection?

What is the best diagnostic approach to take, using which sample types and at what time point during infection?

What is the best regime for therapeutic management of cases?

influence the survival, persistence and transmissibility of $B$. miyamotoi.

To anticipate human infection, consideration of the tick species likely to be encountered is important. An example might be the detected presence of $B$. miyamotoi within I. dentatus ticks that preferentially feed upon birds or lagomorphs and thus present a reduced risk of human infection [31]. Such information would enable instigation of risk prediction, modelling and targeted intervention approaches where justified.

Blood transfusion has been hypothesised as a risk factor for $B$. miyamotoi infection. Experimental studies have demonstrated the ability of $B$. miyamotoi to survive under conditions used for storage of blood transfusion products [100], raising concern that this could provide an additional source of infection (Table 3). Though theoretically possible, clinical cases presenting with acute signs, typically fever and associated non-specific influenza-like features, unlikely would present to donate blood [101]. Quantification of the numbers of spirochaetes present during human infection suggests that levels peak at ca $10^{3}-10^{4}$ B. miyamotoi copies per $\mathrm{mL}$ during the second to third day of illness, then rapidly wane until day eight [22]. These authors suggested that PCR diagnosis was unreliable after the fourth day of clinical signs which would suggest low risk of transfusion related infection.

An enigma of our current understanding is why we fail to see a correlation between clinical cases of $B$. miyamotoiinfection and tick infection prevalence. Human cases have occurred in some areas with relatively low tick infection prevalence, like Yekaterinburg, Russia, while in other countries or areas with higher prevalence in ticks, such as Mongolia or Hannover in Germany, no cases were reported. The reasons are likely to be multifactorial. Tick factors such as feeding preferences or the role of vertebrate hosts in intensifying or negatively impacting transmission could perhaps account for the observations. Another explanation might be differential virulence in humans of the strains involved, as it remains to be solved if different strains/genotypes show differential virulence. Last, the absence of an evident relation between tick and human infection rates could also possibly result from lack of diagnostic ability, proximity to those with active research interest in tick-borne disease, or cases missed due to unspecific symptoms. The clinical features of $B$. miyamotoi indeed lack a diagnostic hallmark, and can potentially be misdiagnosed as granulocytic anaplasmosis [77,102]. Given these difficulties to recognise $B$. miyamotoi infections, it is likely that cases are under-reported. While spontaneous resolution of an infection with $B$. miyamotoi can occur without antimicrobial intervention $[69,103]$, some clinical studies have noted severe infection, with considerable proportions of cases being hospitalised (24\% [78]). Because when cases are diagnosed, they are likely to be promptly treated, the long-term consequences of human infection remain to be determined. While case studies of immunocompromised individuals report notable clinical features $[64,72-74]$, the other risk factors that might influence the clinical progression towards disease are also not clear. Future detailed epidemiological studies of cases detected will enable a more complete clinical picture to unfold.

We also need to be aware of unusual presentations resulting from potential co-infection. The areas reporting cases are likely endemic for a variety of different tick-borne diseases. Clinically, presence of one tickborne pathogen can obscure the concomitant presence of another. Consequently, it is a priority that those suspected of $B$. miyamotoiinfection be also comprehensively screened for other tick-borne pathogens.

Diagnostic methods are nevertheless still widely considered 'research tests' and thus not generally available in more routine clinical settings. When these are possible, a delay in considering $B$. miyamotoi infection might further complicate their interpretation, due to the 
poorly delineated clinical course of human infection. A further problem may be the variability of strains encountered which may affect diagnostic results.

Another problem relates to what the most appropriate diagnostic sample is. Ticks removed from patients have limited diagnostic value in that transmission may not have occurred and this might only be one of several ticks that might have bitten the individual in question. During acute infection, blood samples are a key sample to collect, however samples should be taken as early as possible and certainly before commencement of antimicrobial therapy. Collection of CSF is valuable in cases showing neurological features. This might require concentration of the specimen to improve diagnostic sensitivity $[72,74]$. Serum samples for serological investigation should be collected at all stages, with early sera used for assessment of seroconversion or increasing titre, and later samples for retrospective studies of prior exposure.

As for the therapeutic management of cases, a more comprehensive in vitro evaluation will be possible to guide this, once more isolates become available representing the diversity within this species.

\section{Conclusion}

Our understanding of $B$. miyamotoi and its ecology and infection potential have only recently started to unfold. The incidence of $B$. miyamotoi infection in humans is poorly explored, hampered by the lack of awareness and appropriate diagnostics. Our understanding of the clinical features of infection currently suggest a relatively mild infectious course without long-lasting sequelae for the majority of infected individuals, but with the caveat of being able to cause severe disease in the immunocompromised $[72,74,86]$. Current incidence is likely to be grossly under-reported, suggested by predicted tick bite exposure and tick prevalence data, as well as through the absence of a clinical presentation hallmark, making assessment of the impact of infection challenging.

\section{Acknowledgements}

We acknowledge ECDC for funding support through framework contract 0J/24/04/2014-PROC/2014/023.

\section{Conflict of interest}

None declared.

\section{Authors' contributions}

The initial review of the literature and compiling the review was undertaken by SJC and MVT. All authors (SC; MVT; AE-P; $A P ; A M \& H Z$ ) contributed towards the final preparation and review.

\section{References}

1. Fukunaga M, Takahashi Y, Tsuruta Y, Matsushita O, Ralph $D$, McClelland M, et al. Genetic and phenotypic analysis of Borrelia miyamotoi sp. nov., isolated from the ixodid tick Ixodes persulcatus, the vector for Lyme disease in Japan. Int J Syst Bacteriol. 1995;45(4):804-10. https://doi. org/10.1099/00207713-45-4-804 PMID: 7547303

2. Platonov AE, Karan LS, Kolyasnikova NM, Makhneva NA, Toporkova MG, Maleev VV, et al. Humans infected with relapsing fever spirochete Borrelia miyamotoi, Russia. Emerg Infect Dis. 2011;17(10):1816-23. https://doi.org/10.3201/ eid1710.101474 PMID: 22000350

3. Crowder CD, Carolan HE, Rounds MA, Honig V, Mothes B, Haag $\mathrm{H}$, et al. Prevalence of Borrelia miyamotoi in Ixodes ticks in Europe and the United States. Emerg Infect Dis. 2014;20(10):1678-82. https://doi.org/10.3201/eid2010.131583 PMID: 25280366

4. Takano A, Toyomane K, Konnai S, Ohashi K, Nakao M, Ito T, et al. Tick surveillance for relapsing fever spirochete Borrelia miyamotoi in Hokkaido, Japan. PLoS One. 2014;9(8):e104532. https://doi.org/10.1371/journal.pone.0104532 PMID: 25111141

5. Szekeres S, Lügner J, Fingerle V, Margos G, Földvári G. Prevalence of Borrelia miyamotoi and Borrelia burgdorferi sensu lato in questing ticks from a recreational coniferous forest of East Saxony, Germany. Ticks Tick Borne Dis. 2017;8(6):922-7. https://doi.org/10.1016/j.ttbdis.2017.08.002 PMID: 28843481

6. Barbour AG, Bunikis J, Travinsky B, Hoen AG, Diuk-Wasser MA, Fish D, et al. Niche partitioning of Borrelia burgdorferi and Borrelia miyamotoi in the same tick vector and mammalian reservoir species. Am J Trop Med Hyg. 2009;81(6):1120-31. https://doi.org/10.4269/ajtmh.2009.09-0208 PMID: 19996447

7. Ruyts SC, Frazer-Mendelewska E, Van Den Berge K, Verheyen $\mathrm{K}$, Sprong $\mathrm{H}$. Molecular detection of tick-borne pathogens Borrelia afzelii, Borrelia miyamotoi and Anaplasma phagocytophilum in Eurasian red squirrels (Sciurus vulgaris). Eur J Wildl Res. 2017;63(3):43. https://doi.org/10.1007/ S10344-017-1104-7

8. Hamšíková Z, Coipan C, Mahríková L, Minichová L, Sprong H, Kazimírová M. Borrelia miyamotoi and co-infection with Borrelia afzelii in Ixodes ricinus Ticks and Rodents from Slovakia. Microb Ecol. 2017;73(4):1000-8. https://doi. org/10.1007/s00248-016-0918-2 PMID: 27995301

9. Wagemakers A, Staarink PJ, Sprong H, Hovius JWR. Borrelia miyamotoi: a widespread tick-borne relapsing fever spirochete. Trends Parasitol. 2015;31(6):260-9. https://doi.org/10.1016/j. pt.2015.03.008 PMID: 25892254

10. Iwabu-Itoh Y, Bazartseren B, Naranbaatar O, Yondonjamts E, Furuno K, Lee K, et al. Tick surveillance for Borrelia miyamotoi and phylogenetic analysis of isolates in Mongolia and Japan. Ticks Tick Borne Dis. 2017;8(6):850-7. https://doi. org/10.1016/j.ttbdis.2017.06.011 PMID: 28768603

11. Geller J, Nazarova L, Katargina O, Järvekülg L, Fomenko $\mathrm{N}$, Golovljova I. Detection and genetic characterization of relapsing fever spirochete Borrelia miyamotoi in Estonian ticks. PLoS One. 2012;7(12):e51914. https://doi.org/10.1371/journal. pone.0051914 PMID: 23251652

12. Cook VJ, Fedorova N, Macdonald WP, Lane RS, Barbour AG. Unique strain of Borrelia miyamotoi in Ixodes pacificus ticks, California, USA. Emerg Infect Dis. 2016;22(12):2205-7. https:// doi.org/10.3201/eid2212.152046 PMID: 27479523

13. Jiang B-G, Jia N, Jiang J-F, Zheng Y-C, Chu Y-L, Jiang R-R, et al. Borrelia miyamotoi infections in humans and ticks, Northeastern China. Emerg Infect Dis. 2018;24(2):236-41. https://doi.org/10.3201/eid2402.160378 PMID: 29350133

14. Dibernardo A, Cote T, Ogden NH, Lindsay LR. The prevalence of Borrelia miyamotoi infection, and co-infections with other Borrelia spp. in Ixodes scapularis ticks collected in Canada. Parasit Vectors. 2014;7(1):183. https://doi.org/10.1186/17563305-7-183 PMID: 24731287

15. Wagemakers A, Jahfari S, de Wever B, Spanjaard L, Starink MV, de Vries HJC, et al. Borrelia miyamotoi in vectors and hosts in The Netherlands. Ticks Tick Borne Dis. 2017;8(3):370-4. https://doi.org/10.1016/j.ttbdis.2016.12.012 PMID: 28065617

16. Koetsveld J, Kolyasnikova NM, Wagemakers A, Toporkova MG, Sarksyan DS, Oei A, et al. Development and optimization of an in vitro cultivation protocol allows for isolation of Borrelia miyamotoi from patients with hard tick-borne relapsing fever. Clin Microbiol Infect. 2017;23(7):480-4. https://doi. org/10.1016/j.cmi.2017.01.009 PMID: 28110053

17. Wilhelmsson P, Fryland L, Börjesson S, Nordgren J, Bergström $\mathrm{S}$, Ernerudh J, et al. Prevalence and diversity of Borrelia species in ticks that have bitten humans in Sweden. J Clin Microbiol. 2010;48(11):4169-76. https://doi.org/10.1128/ JCM.01061-10 PMID: 20844223 
18. Mun J, Eisen RJ, Eisen L, Lane RS. Detection of a Borrelia miyamotoi sensu lato relapsing-fever group spirochete from Ixodes pacificus in California. J Med Entomol. 2006;43(1):1203. https://doi.org/10.1603/0022-2585(2006)043[0120:DOABM S]2.0.CO;2 PMID: 16506458

19. Lynn GE, Graham CB, Horiuchi K, Eisen L, Johnson TL, Lane RS, et al. Prevalence and geographic distribution of Borrelia miyamotoi in host-seeking Ixodes pacificus (Acari: Ixodidae) nymphs in Mendocino County, California. I Med Entomol. 2018;55(3):711-6. https://doi.org/10.1093/jme/tjx258 PMID: 29365130

20. Blazejak K, Raulf M-K, Janecek E, Jordan D, Fingerle V, Strube C. Shifts in Borrelia burgdorferi (s.l.) geno-species infections in Ixodes ricinus over a 10-year surveillance period in the city of Hanover (Germany) and Borrelia miyamotoi-specific Reverse Line Blot detection. Parasit Vectors. 2018;11(1):304. https:// doi.org/10.1186/s13071-018-2882-9 PMID: 29776377

21. Khasnatinov MA, Danchinova GA, Takano A, Kawabata H, Ohashi N, Masuzawa T. Prevalence of Borrelia miyamotoi in Ixodes persulcatus in Irkutsk City and its neighboring territories, Russia. Ticks Tick Borne Dis. 2016;7(2):394-7. https://doi.org/10.1016/j.ttbdis.2015.12.016 PMID: 26750571

22. Karan L, Makenov M, Kolyasnikova N, Stukolova O, Toporkova M, Olenkova O. Dynamics of spirochetemia and early PCR Detection of Borrelia miyamotoi. Emerg Infect Dis. 2018;24(5):860-7. https://doi.org/10.3201/eid2405.170829 PMID: 29664394

23. Adeolu M, Gupta RS. A phylogenomic and molecular marker based proposal for the division of the genus Borrelia into two genera: the emended genus Borrelia containing only the members of the relapsing fever Borrelia, and the genus Borreliella gen. nov. containing the members of the Lyme disease Borrelia (Borrelia burgdorferi sensu lato complex). Antonie van Leeuwenhoek. 2014;105(6):1049-72. https://doi. org/10.1007/S10482-014-0164-X PMID: 24744012

24. Margos G, Marosevic D, Cutler S, Derdakova M, Diuk-Wasser $M$, Emler S, et al. There is inadequate evidence to support the division of the genus Borrelia. Int J Syst Evol Microbiol. 2017;67(4):1081-4. https://doi.org/10.1099/ijsem.0.001717 PMID: 27930271

25. Margos G, Gofton A, Wibberg D, Dangel A, Marosevic D, Loh S-M, et al. The genus Borrelia reloaded. PLoS One. 2018;13(12):e0208432. https://doi.org/10.1371/journal. pone.0208432 PMID: 30586413

26. Mukhacheva TA, Salikhova II, Kovalev SY. Multilocus spacer analysis revealed highly homogeneous genetic background of Asian type of Borrelia miyamotoi. Infect Genet Evol. 2015;31:257-62. https://doi.org/10.1016/j.meegid.2015.02.009 PMID: 25697887

27. Siński E, Welc-Falęciak R, Zajkowska J. Borrelia miyamotoi: A human tick-borne relapsing fever spirochete in Europe and its potential impact on public health. Adv Med Sci. 2016;61(2):2556o. https://doi.org/10.1016/j.advms.2016.03.001 PMID: 27100337

28. Salkeld DJ, Nieto NC, Bonilla DL, Yoshimizu MH, Padgett KA. Borrelia miyamotoi infections in small mammals, California, USA. Emerg Infect Dis. 2018;24(12):2356-9. https://doi. org/10.3201/eid2412.171632 PMID: 30457525

29. Marti Ras N, Lascola B, Postic D, Cutler SJ, Rodhain F, Baranton G, et al. Phylogenesis of relapsing fever Borrelia spp. Int J Syst Bacteriol. 1996;46(4):859-65. https://doi. org/10.1099/00207713-46-4-859 PMID: 8863409

30. Vitorino LR, Margos G, Feil EJ, Collares-Pereira M, Zé-Zé $L$, Kurtenbach K. Fine-scale phylogeographic structure of Borrelia lusitaniae revealed by multilocus sequence typing. PLoS One. 2008;3(12):e4002. https://doi.org/10.1371/journal. pone.0004002 PMID: 19104655

31. Hamer SA, Hickling GJ, Keith R, Sidge IL, Walker ED, Tsao Jl. Associations of passerine birds, rabbits, and ticks with Borrelia miyamotoi and Borrelia andersonii in Michigan, U.S.A. Parasit Vectors. 2012;5(1):231. https://doi.org/10.1186/17563305-5-231 PMID: 23057837

32. Yang Y, Yang Z, Kelly P, Li J, Ren Y, Wang C. Borrelia miyamotoi sensu lato in Père David Deer and Haemaphysalis longicornis Ticks. Emerg Infect Dis. 2018;24(5):928-31. https://doi. org/10.3201/eid2405.171355 PMID: 29664385

33. Scoles GA, Papero M, Beati L, Fish D. A relapsing fever group spirochete transmitted by Ixodes scapularis ticks. Vector Borne Zoonotic Dis. 2001;1(1):21-34. https://doi. org/10.1089/153036601750137624 PMID: 12653133

34. Lynn GE, Breuner NE, Eisen L, Hojgaard A, Replogle AJ, Eisen RJ. An immunocompromised mouse model to infect Ixodes scapularis ticks with the relapsing fever spirochete, Borrelia miyamotoi. Ticks Tick Borne Dis. 2019;10(2):352-9. https://doi. org/10.1016/j.ttbdis.2018.11.017 PMID: 30503357
35. Fedorova N, Kleinjan JE, James D, Hui LT, Peeters H, Lane RS. Remarkable diversity of tick or mammalian-associated Borreliae in the metropolitan San Francisco Bay Area, California. Ticks Tick Borne Dis. 2014;5(6):951-61. https://doi. org/10.1016/j.ttbdis.2014.07.015 PMID: 25129859

36. Szekeres S, Docters van Leeuwen A, Tóth E, Majoros G, Sprong $\mathrm{H}$, Földvári G. Road-killed mammals provide insight into tickborne bacterial pathogen communities within urban habitats. Transbound Emerg Dis. 2019;66(1):277-86. https://doi. org/10.1111/tbed.13019 PMID: 30230270

37. Burri C, Schumann O, Schumann C, Gern L. Are Apodemus spp. mice and Myodes glareolus reservoirs for Borrelia miyamotoi, Candidatus Neoehrlichia mikurensis, Rickettsia helvetica, R. monacensis and Anaplasma phagocytophilum? Ticks Tick Borne Dis. 2014;5(3):245-51. https://doi.org/10.1016/j. ttbdis.2013.11.007 PMID: 24582511

38. Cosson J-F, Michelet L, Chotte J, Le Naour E, Cote M, Devillers $\mathrm{E}$, et al. Genetic characterization of the human relapsing fever spirochete Borrelia miyamotoi in vectors and animal reservoirs of Lyme disease spirochetes in France. Parasit Vectors. 2014;7(1):233. https://doi.org/10.1186/1756-3305-7-233 PMID: 24886071

39. Jahfari S, Ruyts SC, Frazer-Mendelewska E, Jaarsma R, Verheyen K, Sprong H. Melting pot of tick-borne zoonoses: the European hedgehog contributes to the maintenance of various tick-borne diseases in natural cycles urban and suburban areas. Parasit Vectors. 2017;10(1):134. https://doi.org/10.1186/ S13071-017-2065-0 PMID: 28270232

40. Heylen D, Fonville M, Docters van Leeuwen A, Stroo A, Duisterwinkel $M$, van Wieren $S$, et al. Pathogen communities of songbird-derived ticks in Europe's low countries. Parasit Vectors. 2017;10(1):497. https://doi.org/10.1186/s13071-0172423-y PMID: 29047399

41. Scott MC, Rosen ME, Hamer SA, Baker E, Edwards H, Crowder $C$, et al. High-prevalence Borrelia miyamotoi infection among [corrected] wild turkeys (Meleagris gallopavo) in Tennessee. Med Entomol. 2010;47(6):1238-42. https://doi.org/10.1603/ ME10075 PMID: 21175079

42. Wodecka B, Rymaszewska A, Skotarczak B. Host and pathogen DNA identification in blood meals of nymphal Ixodes ricinus ticks from forest parks and rural forests of Poland. Exp Appl Acarol. 2014;62(4):543-55. https://doi.org/10.1007/s10493013-9763-X PMID: 24352572

43. Wodecka B, Skotarczak B. Identification of host blood-meal sources and Borrelia in field-collected Ixodes ricinus ticks in north-western Poland. Ann Agric Environ Med. 2016;23(1):5963. https://doi.org/10.5604/12321966.1196853 PMID: 27007518

44. Han S, Hickling GJ, Tsao II. High prevalence of Borrelia miyamotoi among adult blacklegged ticks from white-tailed deer. Emerg Infect Dis. 2016;22(2):316-8. https://doi. org/10.3201/eid2202.151218 PMID: 26811985

45. Kumagai Y, Sato K, Taylor KR, Zamoto-Niikura A, Imaoka K, Morikawa S, et al. A relapsing fever group Borrelia sp. is widely distributed among wild deer in Japan. Ticks Tick Borne Dis. 2018;9(3):465-70. https://doi.org/10.1016/j.ttbdis.2017.12.016 PMID: 29329785

46. Furuno K, Lee K, Itoh Y, Suzuki K, Yonemitsu K, Kuwata R, et al. Epidemiological study of relapsing fever borreliae detected in Haemaphysalis ticks and wild animals in the western part of Japan. PLoS One. 2017;12(3):e0174727. https://doi. org/10.1371/journal.pone.0174727 PMID: 28362864

47. Eisen RJ, Eisen L, Girard YA, Fedorova N, Mun J, Slikas B, et al. A spatially-explicit model of acarological risk of exposure to Borrelia burgdorferi-infected Ixodes pacificus nymphs in northwestern California based on woodland type, temperature, and water vapor. Ticks Tick Borne Dis. 2010;1(1):35-43. https:// doi.org/10.1016/j.ttbdis.2009.12.002 PMID: 20532183

48. Hamer SA, Hickling GJ, Walker ED, Tsao JI. Increased diversity of zoonotic pathogens and Borrelia burgdorferi strains in established versus incipient Ixodes scapularis populations across the Midwestern United States. Infect Genet Evol. 2014;27:531-42. https://doi.org/10.1016/j.meegid.2014.06.003 PMID: 24953506

49. Wilhelmsson P, Lindblom P, Fryland L, Ernerudh J, Forsberg P, Lindgren P-E. Prevalence, diversity, and load of Borrelia species in ticks that have fed on humans in regions of Sweden and Åland Islands, Finland with different Lyme borreliosis incidences. PLoS One. 2013;8(11):e81433. https://doi. org/10.1371/journal.pone.0081433 PMID: 24278437

50. Bunikis J, Barbour AG. Third Borrelia species in white-footed mice. Emerg Infect Dis. 2005;11(7):1150-1. https://doi. org/10.3201/eid1107.041355 PMID: 16032795

51. Taylor KR, Takano A, Konnai S, Shimozuru M, Kawabata H, Tsubota T. Borrelia miyamotoi infections among wild rodents show age and month independence and correlation with Ixodes persulcatus larval attachment in Hokkaido, Japan. Vector 
Borne Zoonotic Dis. 2013;13(2):92-7. https://doi.org/10.1089/ vbz.2012.1027 PMID: 23210636

52. Telford SR 3rd, Goethert HK, Molloy PJ, Berardi VP, Chowdri HR, Gugliotta JL, et al. Borrelia miyamotoi disease: Neither Lyme disease nor relapsing fever. Clin Lab Med. 2015;35(4):867-82. https://doi.org/10.1016/j.cll.2015.08.002 PMID: 26593262

53. van Duijvendijk G, Coipan C, Wagemakers A, Fonville M, Ersöz J, Oei A, et al. Larvae of Ixodes ricinus transmit Borrelia afzelii and B. miyamotoi to vertebrate hosts. Parasit Vectors. 2016;9(1):97. https://doi.org/10.1186/s13071-016-1389-5 PMID: 26896940

54. Rollend L, Fish D, Childs JE. Transovarial transmission of Borrelia spirochetes by Ixodes scapularis: a summary of the literature and recent observations. Ticks Tick Borne Dis. 2013;4(1-2):46-51. https://doi.org/10.1016/j. ttbdis.2012.06.008 PMID: 23238242

55. Richter D, Debski A, Hubalek Z, Matuschka F-R. Absence of Lyme disease spirochetes in larval Ixodes ricinus ticks. Vector Borne Zoonotic Dis. 2012;12(1):21-7. https://doi.org/10.1089/ vbz.2011.0668 PMID: 21923267

56. Breuner NE, Dolan MC, Replogle AJ, Sexton C, Hojgaard A, Boegler KA, et al. Transmission of Borrelia miyamotoi sensu lato relapsing fever group spirochetes in relation to duration of attachment by Ixodes scapularis nymphs. Ticks Tick Borne Dis. 2017;8(5):677-81. https://doi.org/10.1016/j.ttbdis.2017.03.008 PMID: 28501504

57. Boyle WK, Wilder HK, Lawrence AM, Lopez JE. Transmission dynamics of Borrelia turicatae from the arthropod vector. PLoS Negl Trop Dis. 2014;8(4):e2767-2767. https://doi.org/10.1371/ journal.pntd.0002767 PMID: 24699275

58. Sarksyan DS, Platonov AE, Karan LS, Shipulin GA, Sprong $\mathrm{H}$, Hovius JW. Probability of spirochete Borrelia miyamotoi transmission from ticks to humans. Emerg Infect Dis. 2015;21(12):2273-4. https://doi.org/10.3201/eid2112.151097 PMID: 26584357

59. Hofhuis A, Herremans T, Notermans DW, Sprong H, Fonville $M$, van der Giessen JW, et al. A prospective study among patients presenting at the general practitioner with a tick bite or erythema migrans in The Netherlands. PLoS One. 2013;8(5):e64361. https://doi.org/10.1371/journal. pone.0064361 PMID: 23696884

6o. Hofhuis A, Harms M, van den Wijngaard C, Sprong H, van Pelt W. Continuing increase of tick bites and Lyme disease between 1994 and 2009. Ticks Tick Borne Dis. 2015;6(1):69-74. https:// doi.org/10.1016/j.ttbdis.2014.09.006 PMID: 25448421

61. Sarksyan DS, Maleev VV, Platonov AE, Platonova OV, Karan LS. [Relapsing (recurrent) disease caused by Borrelia miyamotoi]. Ter Arkh. 2015;87(11):18-25. https://doi.org/10.17116/ terarkh2015871118-25 PMID: 26821411

62. Krause PJ, Narasimhan S, Wormser GP, Barbour AG, Platonov $A E$, Brancato J, et al. Tick Borne Diseases Group. Borrelia miyamotoi sensu lato seroreactivity and seroprevalence in the northeastern United States. Emerg Infect Dis. 2014;20(7):118390. https://doi.org/10.3201/eid2007.131587 PMID: 24960072

63. Krause PJ, Narasimhan S, Wormser GP, Rollend L, Fikrig E, Lepore $\mathrm{T}$, et al. Human Borrelia miyamotoi infection in the United States. N Engl J Med. 2013;368(3):291-3. https://doi. org/10.1056/NEJMC1215469 PMID: 23323920

64. Sato K, Sakakibara K, Masuzawa T, Ohnishi M, Kawabata H. Case control study: Serological evidence that Borrelia miyamotoi disease occurs nationwide in Japan. J Infect Chemother. 2018;24(10):828-33. https://doi.org/10.1016/j. jiac.2018.06.017 PMID: 30057339

65. Barbour AG. Multiple and Diverse vsp and vlp Sequences in Borrelia miyamotoi, a hard tick-borne zoonotic pathogen. PLoS One. 2016;11(1):e0146283. https://doi.org/10.1371/journal. pone.0146283 PMID: 26785134

66. Teegler A, Herzberger P, Margos G, Fingerle V, Kraiczy P. The relapsing fever spirochete Borrelia miyamotoi resists complement-mediated killing by human serum. Ticks Tick Borne Dis. 2014;5(6):898-901. https://doi.org/10.1016/j. ttbdis.2014.07.011 PMID: 25104575

67. Stone BL, Brissette CA. Host immune evasion by Lyme and relapsing fever borreliae: Findings to lead future studies for Borrelia miyamotoi. Front Immunol. 2017;8:12. https://doi. org/10.3389/fimmu.2017.00012 PMID: 28154563

68. Röttgerding F, Wagemakers A, Koetsveld J, Fingerle V, Kirschfink M, Hovius JW, et al. Immune evasion of Borrelia miyamotoi: CbiA, a novel outer surface protein exhibiting complement binding and inactivating properties. Sci Rep. 2017;7(1):303. https://doi.org/10.1038/s41598-017-00412-4 PMID: 28331202

69. Sudhindra P, Wang G, Schriefer ME, McKenna D, Zhuge J, Krause PJ, et al. Insights into Borrelia miyamotoi infection from an untreated case demonstrating relapsing fever, monocytosis and a positive C6 Lyme serology. Diagn Microbiol
Infect Dis. 2016;86(1):93-6. https://doi.org/10.1016/j. diagmicrobio.2016.06.015 PMID: 27412815

70. Larsson C, Andersson M, Pelkonen J, Guo BP, Nordstrand A, Bergström S. Persistent brain infection and disease reactivation in relapsing fever borreliosis. Microbes Infect. 2006;8(8):2213-9. https://doi.org/10.1016/j. micinf.2006.04.007 PMID: 16782384

71. Andersson $M$, Nordstrand A, Shamaei-Tousi A, Jansson A, Bergström S, Guo BP. In situ immune response in brain and kidney during early relapsing fever borreliosis. J Neuroimmunol. 2007;183(1-2):26-32. https://doi.org/10.1016/j. jneuroim.2006.11.004 PMID: 17184846

72. Boden K, Lobenstein S, Hermann B, Margos G, Fingerle V. Borrelia miyamotoi-associated neuroborreliosis in immunocompromised person. Emerg Infect Dis. 2016;22(9):1617-20. https://doi.org/10.3201/eid2209.152034 PMID: 27533748

73. Hovius JWR, de Wever B, Sohne M, Brouwer MC, Coumou J, Wagemakers A, et al. A case of meningoencephalitis by the relapsing fever spirochaete Borrelia miyamotoi in Europe. Lancet. 2013;382(9892):658. https://doi.org/10.1016/So1406736(13)61644-X PMID: 23953389

74. Gugliotta JL, Goethert HK, Berardi VP, Telford SR 3rd. Meningoencephalitis from Borrelia miyamotoi in an immunocompromised patient. N Engl J Med. 2013;368(3):2405. https://doi.org/10.1056/NEJMoa1209039 PMID: 23323900

75. Sato K, Takano A, Konnai S, Nakao M, Ito T, Koyama K, et al. Human infections with Borrelia miyamotoi, Japan. Emerg Infect Dis. 2014;20(8):1391-3. https://doi.org/10.3201/ eid2008.131761 PMID: 25061761

76. Jobe DA, Lovrich SD, Oldenburg DG, Kowalski TJ, Callister SM. Borrelia miyamotoi infection in patients from upper midwestern United States, 2014-2015. Emerg Infect Dis. 2016;22(8):1471-3. https://doi.org/10.3201/eid2208.151878 PMID: 27434048

77. Chowdri HR, Gugliotta JL, Berardi VP, Goethert HK, Molloy PJ, Sterling SL, et al. Borrelia miyamotoi infection presenting as human granulocytic anaplasmosis: a case report. Ann Intern Med. 2013;159(1):21-7. https://doi.org/10.7326/0003-4819-1591-201307020-00005 PMID: 23817701

78. Molloy PJ, Telford SR 3rd, Chowdri HR, Lepore TJ, Gugliotta JL, Weeks KE, et al. Borrelia miyamotoi disease in the northeastern United States: a case series. Ann Intern Med. 2015;163(2):91-8. https://doi.org/10.7326/M15-0333 PMID: 26053877

79. Krause PJ, Schwab J, Narasimhan S, Brancato J, Xu G, Rich SM. Hard tick relapsing fever caused by Borrelia miyamotoi in a Child. Pediatr Infect Dis J. 2016;35(12):1352-4. https://doi. org/10.1097/INF.0000000000001330 PMID: 27626914

8o. Yamano K, Ito T, Kiyanagi K, Yamazaki H, Sugawara M, Saito T, et al. Case report: Clinical features of a case of suspected Borrelia miyamotoi disease in Hokkaido, Japan. Am J Trop Med Hyg. 2017;97(1):84-7. https://doi.org/10.4269/ajtmh.16-0699 PMID: 28719293

81. Larsson C, Bergström S. A novel and simple method for laboratory diagnosis of relapsing Fever borreliosis. Open Microbiol J. 2008;2(1):10-2. https://doi.org/10.2174/18742858 00802010010 PMID: 19088905

82. Venczel R, Knoke L, Pavlovic M, Dzaferovic E, Vaculova $T$, Silaghi $C$, et al. A novel duplex real-time $P C R$ permits simultaneous detection and differentiation of Borrelia miyamotoi and Borrelia burgdorferi sensu lato. Infection. 2016;44(1):47-55. https://doi.org/10.1007/s15010-015-0820-8 PMID: 26168860

83. Wroblewski D, Gebhardt L, Prusinski MA, Meehan LJ, Halse TA, Musser KA. Detection of Borrelia miyamotoi and other tick-borne pathogens in human clinical specimens and Ixodes scapularis ticks in New York State, 2012-2015. Ticks Tick Borne Dis. 2017;8(3):407-11. https://doi.org/10.1016/j. ttbdis.2017.01.004 PMID: 28131594

84. Schwan TG, Schrumpf ME, Hinnebusch BJ, Anderson DE Jr, Konkel ME. GlpQ: an antigen for serological discrimination between relapsing fever and Lyme borreliosis. J Clin Microbiol. 1996;34(10):2483-92. PMID: 8880505

85. Krause PJ, Carroll M, Fedorova N, Brancato J, Dumouche $C$, Akosa F, et al. Human Borrelia miyamotoi infection in California: Serodiagnosis is complicated by multiple endemic Borrelia species. PLoS One. 2018;13(2):e0191725. https://doi. org/10.1371/journal.pone.0191725 PMID: 29420552

86. Krause PJ, Fish D, Narasimhan S, Barbour AG. Borrelia miyamotoi infection in nature and in humans. Clin Microbiol Infect. 2015;21(7):631-9. https://doi.org/10.1016/j. cmi.2015.02.006 PMID: 25700888

87. Wagemakers A, Koetsveld J, Narasimhan S, Wickel M, Deponte K, Bleijlevens B, et al. Variable major proteins as targets for specific antibodies against Borrelia miyamotoi. 
J Immunol. 2016;196(10):4185-95. https://doi.org/10.4049/ jimmunol.1600014 PMID: 27076681

88. Koetsveld J, Kolyasnikova NM, Wagemakers A, Stukolova OA, Hoornstra D, Sarksyan DS, et al. Serodiagnosis of Borrelia miyamotoi disease by measuring antibodies against GlpQ and variable major proteins. Clin Microbiol Infect. 2018;24(12):1338.e1-7. https://doi.org/10.1016/j. cmi.2018.03.009 PMID: 29550499

89. Vayssier-Taussat M, Moutailler S, Michelet L, Devillers E, Bonnet $S$, Cheval J, et al. Next generation sequencing uncovers unexpected bacterial pathogens in ticks in western Europe. PLoS One. 2013;8(11):e81439. https://doi.org/10.1371/journal. pone.0081439 PMID: 24312301

90. Borgoyakov VY, Fomenko NV, Panov VV, Chikova ED. Infestation of taiga ticks with borrelias in the territory of Novosibirsk Scientific Center (Siberian Branch, Russian Academy of Sciences). Entomol Rev (Engl Transl). 2011;91(3):396-404. https://doi.org/10.1134/So013873811030158

91. Wagemakers A, Oei A, Fikrig MM, Miellet WR, Hovius JW. The relapsing fever spirochete Borrelia miyamotoi is cultivable in a modified Kelly-Pettenkofer medium, and is resistant to human complement. Parasit Vectors. 2014;7(1):418. https://doi. org/10.1186/1756-3305-7-418 PMID: 25189195

92. Margos G, Stockmeier S, Hizo-Teufel C, Hepner S, Fish D, Dautel $\mathrm{H}$, et al. Long-term in vitro cultivation of Borrelia miyamotoi. Ticks Tick Borne Dis. 2015;6(2):181-4. https://doi. org/10.1016/j.ttbdis.2014.12.001 PMID: 25561082

93. Koetsveld J, Draga ROP, Wagemakers A, Manger A, Oei A, Visser CE, et al. In vitro susceptibility of the relapsing-fever spirochete Borrelia miyamotoi to antimicrobial agents. Antimicrob Agents Chemother. 2017;61(9):eo0535-17. https:// doi.org/10.1128/AAC.00535-17 PMID: 28674060

94. Ates L, Hanssen-Hübner C, Norris DE, Richter D, Kraiczy P, Hunfeld K-P. Comparison of in vitro activities of tigecycline, doxycycline, and tetracycline against the spirochete Borrelia burgdorferi. Ticks Tick Borne Dis. 2010;1(1):30-4. https://doi. org/10.1016/j.ttbdis.2009.11.004 PMID: 21771509

95. Hunfeld K-P, Kraiczy P, Kekoukh E, Schäfer V, Brade V. Standardised in vitro susceptibility testing of Borrelia burgdorferi against well-known and newly developed antimicrobial agents--possible implications for new therapeutic approaches to Lyme disease. Int I Med Microbiol. 2002;291(Suppl 33):125-37. https://doi.org/10.1016/S14384221(02)80024-8 PMID: 12141737

96. Hunfeld K-P, Ruzic-Sabljic E, Norris DE, Kraiczy P, Strle F. In vitro susceptibility testing of Borrelia burgdorferi sensu lato isolates cultured from patients with erythema migrans before and after antimicrobial chemotherapy. Antimicrob Agents Chemother. 2005;49(4):1294-301. https://doi.org/10.1128/ AAC.49.4.1294-1301.2005 PMID: 15793100

97. Butler T. The Jarisch-Herxheimer Reaction After Antibiotic Treatment of spirochetal infections: A review of recent cases and our understanding of pathogenesis. Am J Trop Med Hyg. 2017;96(1):46-52. https://doi.org/10.4269/ajtmh.16-0434 PMID: 28077740

98. Kurtenbach K, Peacey M, Rijpkema SGT, Hoodless AN, Nuttall PA, Randolph SE. Differential transmission of the genospecies of Borrelia burgdorferi sensu lato by game birds and small rodents in England. Appl Environ Microbiol. 1998;64(4):116974. PMID: 9546150

99. Diuk-Wasser MA, Vannier E, Krause PJ. Coinfection by Ixodes tick-borne pathogens: Ecological, epidemiological, and clinical consequences. Trends Parasitol. 2016;32(1):30-42. https://doi. org/10.1016/j.pt.2015.09.008 PMID: 26613664

100. Thorp AM, Tonnetti L. Distribution and survival of Borrelia miyamotoi in human blood components. Transfusion. 2016;56(3):705-11. https://doi.org/10.1111/trf.13398 PMID: 26689144

101. Pavia CS, Plummer MM. Transfusion-associated Lyme disease - Although unlikely, it is still a concern worth considering. Front Microbiol. 2018;9:2070-2070. https://doi.org/10.3389/ fmicb.2018.02070 PMID: 30233543

102. Jahfari S, Herremans T, Platonov AE, Kuiper H, Karan LS, Vasilieva 0 , et al. High seroprevalence of Borrelia miyamotoi antibodies in forestry workers and individuals suspected of human granulocytic anaplasmosis in the Netherlands. New Microbes New Infect. 2014;2(5):144-9. https://doi. org/10.1002/nmi2.59 PMID: 25356364

103. Hoornstra D, Koetsveld J, Sprong H, Platonov AE, Hovius JW. Borrelia miyamotoi disease in an immunocompetent patient, Western Europe. Emerg Infect Dis. 2018;24(9):1770-2. https:// doi.org/10.3201/eid2409.180806 PMID: 30124426

104. Rar V, Livanova N, Tkachev S, Kaverina G, Tikunov A, Sabitova $Y$, et al. Detection and genetic characterization of a wide range of infectious agents in Ixodes pavlovskyi ticks in Western
Siberia, Russia. Parasit Vectors. 2017;10(1):258. https://doi. org/10.1186/s13071-017-2186-5 PMID: 28545549

105. Mukhacheva TA, Kovalev SY. Borrelia spirochetes in Russia: Genospecies differentiation by real-time PCR. Ticks Tick Borne Dis. 2014;5(6):722-6. https://doi.org/10.1016/j. ttbdis.2014.05.016 PMID: 25108777

106. Cochez C, Heyman P, Heylen D, Fonville M, Hengeveld P, Takken W, et al. The presence of Borrelia miyamotoi, a relapsing fever spirochaete, in questing Ixodes ricinus in Belgium and in the Netherlands. Zoonoses Public Health. 2015;62(5):331-3. https://doi.org/10.1111/zph.12154 PMID: 25212814

107. Fonville M, Friesema IHM, Hengeveld PD, Docters van Leeuwen A, Jahfari S, Harms MG, et al. Human exposure to tickborne relapsing fever spirochete Borrelia miyamotoi, the Netherlands. Emerg Infect Dis. 2014;20(7):1244-5. https://doi. org/10.3201/eid2007.131525 PMID: 24963562

108. Padgett K, Bonilla D, Kjemtrup A, Vilcins I-M, Yoshimizu $\mathrm{MH}$, Hui L, et al. Large scale spatial risk and comparative prevalence of Borrelia miyamotoi and Borrelia burgdorferi sensu lato in Ixodes pacificus. PLoS One. 2014;9(10):e110853. https://doi.org/10.1371/journal.pone.0110853 PMID: 25333277

\section{License, supplementary material and copyright}

This is an open-access article distributed under the terms of the Creative Commons Attribution (CC BY 4.0) Licence. You may share and adapt the material, but must give appropriate credit to the source, provide a link to the licence and indicate if changes were made.

Any supplementary material referenced in the article can be found in the online version.

This article is copyright of the authors or their affiliated institutions, 2019. 